\title{
LA PRODUCCIÓN DE METABOLITOS SECUNDARIOS EN LA FAMILIA BRASSICACEAE
}

Fecha de recepción: 29 de julio de 2013 • Fecha de aceptación: 16 de septiembre de 2013

\section{SECONDARY METABOLITES PRODUCTION BY BRASSICACEAE FAMILY}

Vargas-Rincón, C. • Sánchez-León, G. ${ }^{1} \bullet$ Jiménez, P.1,2

\section{RESUMEN}

La familia botánica Brassicaceae no sólo posee una reconocida importancia económica, sino también académica y ecológica. Muchos miembros de esta familia son utilizados como alimento, y varios de ellos también se utilizan como organismos modelo para el estudio del reino Plantae. Una característica resaltante de esta familia es la producción de diversos metabolitos, que pueden conferir ventajas en diferentes papeles ecológicos. Aún cuando posiblemente los más conocidos son los glucosinolatos, otros metabolitos también presentan características interesantes desde los puntos de vista tanto biológico como químico. Esta revisión tiene como objetivo estimular estudios relacionados con las actividades de estos metabolitos y sus posibles aplicaciones en la agricultura.

Palabras clave: Brassicaceae, glucosinolatos, metabolismo secundario.

\section{ABSTRACT}

The botanical family Brassicaceae not only has considerable economic importance, but also academic and ecological relevance. Many members of this family are used as food, and several of them are also used as model organisms for the study of the kingdom Plantae. A striking feature of the family is the production of various metabolites, which confer the family advantages in different ecological roles. Although possibly the best known of them are the glucosinolates, other metabolites also exhibit interesting features considered from the biological and chemical points of view. This review aims to stimulate further studies related to the activities of the metabolites, and their potential applications in agriculture.

Keywords: Brassicaceae, glucosinolates, secondary metabolism.

1 Grupo Inquibio, Laboratorio de Fitopatología, Facultad de Ciencias Básicas y Aplicadas, Universidad Militar Nueva Granada. Km 2 Vía Cajicá- Zipaquirá, Cundinamarca, Colombia

2 Autor para correspondencia: pedro.jimenez@unimilitar.edu.co 


\section{LA FAMILIA BRASSICACEAE: GENERALIDADES Y TAXONOMÍA}

La familia Brassicaceae es un grupo de angiospermas, presente en regiones montañosas y regiones tropicales de todos los continentes, excepto en la Antártida (Anjum et al. 2011). Este grupo de plantas se encuentran bien definido por la estructura característica de su flor, a cual se distingue por presentar cuatro pétalos dispuestos de manera diagonalmente opuesta, que vista desde arriba recuerda la forma de una cruz griega, de allí el antiguo nombre de la familia Cruciferae (Anjum et al. 2011; Franzke at al., 2011). Esta familia incluye especies que poseen un especial interés científico, económico y agronómico, incluyendo especies modelo de estudio biológico (Arabidopsis thaliana y varias especies del género Brassica), así como aquellas que son ampliamente cultivadas (brócoli, canola, coliflor, colza y diversos rábanos) (Anjum et al. 2011). Varios de sus taxones son conocidos por su habilidad de hiperacumular metales y su tolerancia a estos (Arabidopsis spp. y Noccaea caerulescens), autoincompatibilidad y la evolución del genoma (Arabidopsis lyrata y A. suecica), hábito e interacciones planta-insecto y planta-patógeno (Arabis alpine), arquitectura de la planta y adaptación al gradiente de agua (Cardamine hirsute), entre otras características (Anjum et al. 2011; Franzke et al., 2011).La familia incluye también más de 120 especies de arvenses, algunas de ellas consideradas importantes malezas agrícolas cosmopolitas (Sinapsis arvensis), otros conforman complejos cultivos-malezas (Raphanus sativus - Raphanus raphanistrum), y algunas son capaces de intercambiar genes, incluidos transgenes, con cultivos bajo condiciones de campo, lo cual puede llevar al aumento potencial de especies de arvenses (Warwick, 2011).

En el sistema Angiosperm Phylogeny Group o sistema APG, las Brassicaceae se han clasificado en el clado Eurosida II, en el orden Brassicales, que se caracteriza por la presencia de glucosinolatos, que contienen azufre (Anjum et al. 2011). La división taxonómica dentro de la familia ha sido un aspecto muy estudiado a todos los niveles. En efecto, las clasificaciones propuestas a partir de mediados del siglo XIX fueron consideradas poco satisfactorias, pues se apoyaban sólo en características morfológicas, lo que es cada día es menos aceptado de no venir acompañado de estudios moleculares. En consecuencia, se han explorado diferentes técnicas moleculares para establecer mejor las relaciones filogenéticas, llevando esto a que las plantas pertenecientes a la familia se han organizado en tribus (Appel y Al-Shehbaz, 2003). Como resultado de todo el esfuerzo taxonómico la familia Brassicaceae incluye 338 géneros y alrededor de 3709 especies aceptadas, distribuidas alrededor del mundo (Warwick et al. 2006). Respecto a la historia evolutiva de la familia, Franke et al. (2011) muestran una excelente revisión del tema filogenético, en la cual resalta la propuesta de eventos de duplicación completa del genoma y sus consecuencias en la estructura actual de la familia, lo cual confiere más robustez a la clasificación actual.

\section{Usos de las plantas de la familia Brassicaceae}

Algunos géneros de importancia en la familia Brassicaceae son Brassica y géneros estrechamente relacionados, tales como Camelina, Ceratocnemum, Coincya, Crambe, Eruca, Raphanus y Rapistrum (Tabla 1). Dentro del género Brassica se incluyen 35 especies de las cuales la mayoría son hierbas anuales y algunas perennes (Warwick, 2011). En el género Camelina, que incluye actualmente 11 especies, se destaca C. sativa (tabla 1). Crambe es otro de los géneros económicamente importantes en esta familia (Warwick, 2011), compuesto por cerca de 39 especies (The Plant List, 2013), con algunas de importancia comercial en 
Tabla 1. Descripción de los usos de algunas especies de la familia Brassicaceae.

\begin{tabular}{|c|c|c|}
\hline Especies & Uso & Referencia \\
\hline $\begin{array}{l}35 \text { especies del } \\
\text { género Brassica. } \\
\text { Ejemplos: } \\
\text { B. nigra } \\
\text { B. juncea } \\
\text { B. carinata } \\
\text { B.rapa, B. napus y B. } \\
\text { oleracea. } \\
\text { Camelina sativa }\end{array}$ & $\begin{array}{l}\text { Las plantas poseen raíces, tallos, hojas, brotes, flores y se- } \\
\text { millas comestibles, los cuales son fuente de aceite e incluso } \\
\text { algunas son ornamentales } \\
\text { - Especie cultivada durante siglos en Europa para obtener } \\
\text { aceite, utilizado con fines culinarios y en lámparas. } \\
\text { - Presenta adaptaciones ante diversas condiciones climáti- } \\
\text { cas, en suelos nutricionalmente pobres y resistencia a va- } \\
\text { rias enfermedades y plagas } \\
\text { - Actualmente, en Europa se cultiva por su potencial como } \\
\text { alimento, y en industrias de pintura, tintes, cosméti- } \\
\text { cos y biocombustible, mientras que en América se está } \\
\text { cultivando a modo de prueba, por su potencial como } \\
\text { biocombustible }\end{array}$ & $\begin{array}{l}\text { Warwick, } 2011 \\
\text { Facciola, } 1990 \\
\text { Kugel y Falk, } 2006 \\
\text { Warwick, } 2011\end{array}$ \\
\hline Crambe abyssinica & $\begin{array}{l}\text { Obtención de aceites a partir de las semillas, fabricación de } \\
\text { lubricantes (eurocamida) y nylon. }\end{array}$ & Warwick, 2011 \\
\hline Eruca sativa & $\begin{array}{l}\text { Uso como ensalada fresca o como verdura cocida, y del } \\
\text { prensado de su semilla se obtiene un aceite con usos cos- } \\
\text { méticos, lubricante, y medicinal }\end{array}$ & Warwick, 2011 \\
\hline Raphanus sativus & $\begin{array}{l}\text { Se obtienen raíces y vainas de semillas comestibles, para } \\
\text { alimentar animales o como abono verde }\end{array}$ & (Warwick, 2011). \\
\hline Sinapsis alba & $\begin{array}{l}\text { 69- Semillas para la producción de mostaza } \\
\text { 70- Uso como forraje fresco y abono verde }\end{array}$ & $\begin{array}{l}\text { Warwick et al. } \\
2006, \text { Warwick, } \\
2011\end{array}$ \\
\hline Matthiola incana & Obtención de ácidos grasos omega3 & Yaniv et al. 1997 \\
\hline
\end{tabular}

aplicaciones industriales (Erickson y Bassin, 1990) (tabla 1). Un ejemplo es C. abyssinica cuyo cultivo inició en la antigua URSS y se ha investigado en diferentes regiones del mundo como Estados Unidos, los Países Bajos y Canadá (Warwick, 2011).

En el género Eruca, compuesto por sólo tres especies (The Plant List, 2013), encontramos plantas consideradas como malezas, sin embargo en los últimos años han sido revaloradas por su uso en la cocina moderna, por ejemplo la aurugula o rúculas.
Se destaca E. sativa (syn. E. vesicaria subsp. sativa (Miller) Thell.) una hierba anual (Warwick, 2011) (Tabla 1). Por su parte, el género Raphanus incluye actualmente sólo dos especies, el rábano ( $R$. sativus) cuyo cultivo se ha documentado al menos hasta el antiguo Egipto y el rábano silvestre ( $R$. Raphanistrum) (Warwick, 2011) (Tabla 1). Sinapsis, cuya especie más representativa es $S$. alba es cultivada en muchos países de Europa y América del Norte, debido a sus varios usos (Warwick et al., 2006; Warwick, 


\begin{tabular}{|c|c|c|}
\hline Lesquerella fendleri & $\begin{array}{l}\text { Se puede cultivar con facilidad en las tierras áridas de Amé- } \\
\text { rica del Norte para la obtención de aceites }\end{array}$ & Salywon et al. 2005 \\
\hline Lepidium sativum & $\begin{array}{l}\text { Propiedades saludables de los alimentos medicinales y } \\
\text { funcionales }\end{array}$ & Warwick, 2011 \\
\hline $\begin{array}{l}\text { Brassica fruticulosa } \\
\text { (silvestre) }\end{array}$ & $\begin{array}{l}\text { Estudiada por su diversificación vegetal en las regiones } \\
\text { mediterraneas }\end{array}$ & Warwick, 2011 \\
\hline $\begin{array}{l}\text { Capsella bursa-pastoris } \\
\text { (Europa y Asia), } \\
\text { Cochlearia arctica y } \\
\text { C. officinalis (Europa), } \\
\text { Coningia orientalis } \\
\text { (Europa), Descurainia } \\
\text { sophia (Afganistán, } \\
\text { China), Erysimum } \\
\text { cheiri, y E. diffusum } \\
\text { (India, Irak, Rusia), } \\
\text { Hesperis matronalis } \\
\text { (Europa), Lepidium } \\
\text { meyenii (América del } \\
\text { Sur), Lobularia maritima } \\
\text { (India) y Rorippa indica } \\
\text { (China, Vietnam) }\end{array}$ & Uso popular medicinal & $\begin{array}{c}\text { Mencionados sin } \\
\text { mayor explicación en } \\
\text { casi todos los traba- } \\
\text { jos citados en esta } \\
\text { tabla. }\end{array}$ \\
\hline
\end{tabular}

2011). Otros de los cultivos de Brassicaceae incluyen a Armoracia rusticana, Diplotaxis spp., Eutrema wasabi, Lepidium sativum, L. meyenii, Nasturtium officinale, Orychophragmus violaceus. Algunas son cultivadas como ornamentales y otras como cultivos oleaginosos industriales (Angelini et al. 1997; Huang et al., 1999) (Tabla 1).

Un papel desempeñado por algunos miembros de esta familia es su actuación como arvenses, lo cual si bien no es un uso ocurre frecuentemente y es de alto impacto en la agricultura. En Colombia se presentan especies tales como Brassica spp., Capsella bursa-pastoris, Lepidium bipinnatifidum, y Raphanus raphanistrum (Fuentes y Romero, 1991; Arrieta, 2000; Plaza y Pedraza, 2007) que son consideradas arvenses y generan pérdidas económicas importantes. Un efecto estudiado es la disminución del rendimiento de cultivos tales como el aguacate, algunos cítricos, curuba, granadilla, guanábana, piña, mango, mora, papaya (Fuentes y Romero, 1991) y uchuva (Plaza y 
Pedraza, 2007). También se consideran malezas de hortalizas como arveja, cebolla tanto de bulbo como larga (junca), espárragos, habichuela, pimentón, tomate y en otros cultivos como frijol, yuca, plátano, cacao (Fuentes y Romero, 1991) y papa (Arrieta, 2000). Es oportuno recordar que considerar una especie vegetal como maleza responde a un criterio antropocéntrico y subjetivo, que sigue la definición: "plantas que crecen siempre o de forma predominante en situaciones marcadamente alteradas por el hombre y que resultan no deseables por éste, en un lugar y momentos oportunos" (Arrieta, 2000), obviando cualquier otro potencial que pudieran presentar, como se ha mostrado arriba.

Metabolitos en la familia Brassicaceae: producción y efectos de factores bióticos y abióticos

Tres grupos químicos importantes son producidos por las plantas: fenoles, terpenoides y compuestos orgánicos que contienen nitrógeno (Taiz y Zieger, 2010; Walters 2010). Los terpenos son sintetizados a partir de la ruta del mevalonato o la del metileritritol fosfato (Taiz y Zieger, 2010; Walters 2010). El primero se encuentra en el citosol y es precursor en la producción de sesquiterpenos, triterpenos, esteroles y politerpenos, mientras que el último se encuentra generalmente en los plastidios, y es precursor en la ruta que lleva a isoprenos, monoterpenos, diterpenos y carotenoides (Lichtenthaler, 1999; Taiz y Zieger, 2010). Un segundo grupo de metabolitos son los compuestos fenólicos, los cuales son sintetizados a partir de la ruta del ácido shikímico o la del ácido malónico (Taiz y Zieger, 2010; Walters 2010). Por último, tenemos los compuestos orgánicos que contienen nitrógeno o azufre y que son sintetizados a partir de aminoácidos e incluyen glucósidos cianogénicos, glucosinolatos o alcaloides (Jahangir et al. 2009; Anjum et al. 2011). En la familia Brassicaceae, los glucosinolatos son metabolitos que ocurren de manera abundante y característica (Jahangir et al.
2009), gracias a la acción de la enzima mirosinasa producen isotiocianatos, nitrilos y otros compuestos, cuya concentración varía según el órgano, edad de la planta y condiciones ambientales y que poseen diversas actividades (Walters, 2010).

Muchos de estos metabolitos actúan como las defensas químicas de las plantas y se clasifican por su presencia en dos grupos. El primero incluye las que pueden ocurrir de manera permanente, ser constitutivas, y están presentas en las superficies de los tejidos o almacenadas para ser liberadas al ser necesarias, mientras que el segundo grupo incluye aquellas cuya síntesis puede ser activada como respuesta a un ataque, es decir pueden ser inducidas (Agrios, 2005). Las preexistentes son las primeras que actúan cuando un patógeno ataca, pero hay casos en los que estas no son suficientes y la planta inicia la producción de todo un arsenal químico. En algunos casos se pueden acumular compuestos fenólicos, taninos o de tipo ácido graso como dienos, en células de frutos jóvenes, hojas, raíces, o semillas, razón por la cual se cree que éstos proporcionan resistencia a los tejidos frente a diversos patógenos (Walters, 2010).

\section{Compuestos fenólicos}

Se ha propuesto que estos compuestos tienen actividad antioxidante en el sistema de defensa de la planta y que adicionalmente sirven de apoyo al sistema de desintoxicación dependiente de ascorbato (Sakihama et al. 2002). Esto se dedujo a partir de estudios realizados en células de Arabidopsis, en los cuales se determinó la velocidad de absorción y concentración de compuestos fenólicos, al ser inducidas respuestas de hipersensibilidad en las plantas (Soylu, 2006). Relacionado con esto ocurre otro fenómeno como es la resistencia sistémica inducida (RSI), la cual es conocida y discutida en muchos artículos científicos los cuales, aunque importantes, escapan del interés de este trabajo. La RSI ha sido 
extensamente estudiada a partir del sistema Arabidopsis thaliana, y aun cuando se ha mencionado que incluye la producción de compuestos fenólicos en el proceso de establecimiento, generalmente se discuten otros aspectos de la bioquímica del fenómeno mas orientados a la regulación de la expresión de proteínas relacionadas con la patogenicidad (Heil y Bostock, 2002; Choudhary et al., 2007; Thakur y Sohal, 2013; Naznin et al., 2014).

\section{Compuestos fenólicos y factores bióticos}

El conjunto de metabolitos que es liberado cuando se produce infección por microorganismos, difiere del ambiente químico del tejido infectado y del mecanismo de acción del microorganismo que ataca la planta (Jahangir et al. 2008; Vereecke et al. 1997). Por ejemplo en plantas de Brassica rapa infectadas con diferentes especies de bacterias tales como Bacillus subtilis, Escherichia coli, Salmonella typhimurium, Shigella flexneri, y Staphylococcus aureus, se encontraron cambios metabólicos, de la planta, que dependían de las especies inoculadas, aunque en todos los casos se evidenció el incremento de sinapol-malato y cafeoil-malato (Jahangir et al. 2008). Un ejemplo de respuesta ante el ataque por herbívoros, la alimentación por parte de un áfido, implica la producción de compuestos fenólicos característicos dependiendo de la saliva que queda alrededor del sitio de penetración
(Miles, 1999). La biosíntesis de compuestos fenólicos ha demostrado incrementar la actividad de enzimas relacionadas con las defensas de la plantas, así como acumulación de los productos de estas enzimas, bien sea por la acción del jasmonato de metilo o por herbivoría (Jahangir et al. 2009). Para comprobar esto Liang et al. (2006), sometieron hojas de $B$. rapa a la presencia de jasmonato de metilo, y lograron identificar la producción por parte de las hojas de cinco fenil propanoides conjugados con malato (5-hidroxiferuloyl-cafeoil-cumaroilferuloil-sinapoil), junto con un incremento en los niveles de hidroxicinamatos y fenilpropanoides. Jahangir et al. (2009) mostraron que la edad de la planta también afecta el patrón de fenoles, al encontrar que en hojas jóvenes de B. oleracea hay 15 compuestos, cinco derivados de kaempferol y 10 derivados de ácido cinámico, mientras que en hojas viejas se detectó el ácido 3-p-cumaroilquinico y 13 derivados de kaempferol, hallando sólo dos compuestos derivados de kaempferol comunes en los dos de grupos de edad. Por su parte Vallejo et al. (2003) encontraron que en cultivares de brócoli había incremento de compuestos fenólicos coincidiendo con el desarrollo de las inflorescencias. Todo estos hallazgos apuntan a entender la edad de la planta como un eventual factor de estrés biótico aún poco explorado a juzgar por la aparente baja mención en la literatura.

\section{Un efecto estudiado es la disminución del rendimiento de cultivos} tales como el aguacate, algunos cítricos, curuba, granadilla, guanábana, piña, mango, mora, papaya (Fuentes y Romero, 1991) y uchuva (Plaza y Pedraza, 2007). 
Los esteroles han sido reconocidos no sólo como precursores de brassinoesteroides y constituyentes de la membrana, sino que también son moduladores en el desarrollo de la planta (Jahangir et al. 2009).

\section{Compuestos fenólicos y factores abióticos}

Un factor que influye en la variedad de compuestos fenólicos producidos es la disponibilidad de nutrientes, por ejemplo el estrés producido por nitrógeno provoca la expresión de genes de la ruta de los flavonoides, mientras que para el caso de la disponibilidad de nitrato la ruta directamente afectada es la de los fenilpropanoides (Sousa et al. 2008). Se ha mostrado también que en el caso de la fertilización con azufre, el contenido de fenol aumenta entre 96-111 mg y el de ácido gálico a $100 \mathrm{~g}$ del peso fresco en B. rapa (Jahangir et al. 2009). Otros factores ambientales, como temperatura y luz, son desencadenantes de vías biosintéticas, de manera que las concentraciones de compuestos fenólicos se incrementan cuando las plantas están expuestas a la luz solar (Jahangir et al. 2009). Un ejemplo claro es el efecto de estos factores sobre el contenido de flavonoides (Schonhof et al. 2007). Estos compuestos, además de ser parte de los metabolitos, inducidos en respuesta a estrés tanto abiótico como biótico, hacen parte de los pigmentos de las flores (Taiz y Zieger, 2010).En repollo rojo (Brassica oleraceae) se ha demostrado que la radiación UV-B induce a una mayor producción de fenoles solubles (Gitz et al. 1998). Adicionalmente, esta radiación incrementa el número de flavonoides en Sinapis alba y en Nasturtium officinale, en el caso de S. alba la quercetina incrementa 10 veces (Reifenrath y Muller, 2007). Para la especie B. napus, irradiada con UV-B, se ha reportado un incremento en la cantidad de flavonoides entre 70 y $150 \%$, de ellos, cuatro flavonoides fueron identificados como glucósidos de quercetina y kaempferol (Jahangir et al. 2009). En otro estudio Wilson et al. (2001), confirmaron que la acumulación de quercetina está relacionada con la tolerancia de la planta a la radiación UV-B. Las condiciones de temperatura en post-cosecha también influyen en el perfil metabólico en las plantas (Jahangir et al. 2009). Por ejemplo, el contenido de luteína en brócoli incrementa cuando se mantiene en temperaturas que oscilan entre 7 y $13^{\circ} \mathrm{C}$ (Schonhof et al. 2007). En brócoli, col de Bruselas, col rizada, y coliflor blanco se observó que a medida que aumentaba la actividad antioxidante disminuía la pérdida de polifenoles, mientras que el congelamiento incrementa los niveles de polifenoles, como forma de respuesta de la planta al estrés (Sikora et al. 2008). Por su parte, Lo Scalzo et al. (2008), describen una comportamiento notorio pues demuestran que ocurre una reducción de antocianinas totales en el coliflor, y la formación de isómeros, al aplicar diferentes pre-tratamientos térmicos, excepto cuando se calentó el material en microondas.

\section{Esteroides}

Los brassinoesteroides son un grupo de compuestos que ocurren naturalmente en las plantas, confiriéndole una amplia gama de actividades biológicas, adicionales a la tolerancia contra un amplio espectro de estreses bióticos y abióticos (Krishna, 
2003). Los esteroles han sido reconocidos no sólo como precursores de brassinoesteroides y constituyentes de la membrana, sino que también son moduladores en el desarrollo de la planta (Jahangir et al. 2009). Como ejemplo tenemos el resultado de tratar B. napus con epibrasinolida, un brassinoesteroide, el cual incrementa la tolerancia a varios estreses ambientales como la sequía y el frío. También en $A$. thaliana, se encontró que esta epibrasinolida ayuda a superar la inhibición de germinación de las semillas causada por estrés salino (Dhaubhadel et al. 1999).

Los brassinoesteroides adicionalmente protegen la integridad de la membrana, en las semillas de rábano ( $R$. sativus), del estrés oxidativo inducido por cadmio, minimizando el impacto del oxígeno reactivo, debido al incremento de la actividad enzimática antioxidante, resultando un mecanismo de defensa contra el estrés oxidativo (Jahangir et al. 2009). Por otra parte, se ha reportado que la expresión génica de la sulfotransferasa es inducida por ácido salicílico, sugiriendo que hay un incremento en la actividad de una proteína antimicrobial, haciendo que las plantas respondan a la infección, modulando procesos de crecimiento y desarrollo dependientes de esteroides (Rouleau et al. 1999).

\section{Fitoalexinas}

A pesar de que muchas fitoalexinas poseen naturaleza fenólica, en este trabajo se separan dada la importancia de cada grupo de compuestos en esta familia botánica. Las fitoalexinas fueron descritas por primera vez por Müller y Börger en 1940, en un estudio que realizaban sobre la interacción entre Phytophthora infestans y Solanum tuberosum (García y Pérez, 2003; Pedras y Ahiahonu, 2005). Muchos de estos compuestos son derivados de la ruta biosintética de los fenilpropanoides y estructuralmente son muy diversos, así como sus actividades biológicas (Jahangir et al. 2009). Tienen bajo peso molecular y algunos actúan como compuestos antimicrobianos (Pedras y Ahiahonu, 2005; Ahuja et al. 2012) y se consideran parte del mecanismo de defensa de las plantas (Rodov et al. 1995; Arras y Sanna, 1999; Ortuño et al. 2006) y para algunos autores estas son elementos claves en el mecanismo de resistencia a infección (Oku y Shiraishi, 1995; Hammerschmidt, 1999). Son sintetizadas por angiospermas y dicotiledóneas, en 16 familias, siendo las familias Brassicaceae, Leguminosae y Solanaceae, en las cuales se han identificado más fitoalexinas (García y Pérez, 2003; Ahuja et al. 2012). La síntesis de estos compuestos, en respuesta de defensa, es inducida por diferentes especies moleculares que pueden funcionar como señal, en las que se incluyen los ácidos grasos, poli y oligosacáridos, polipéptidos, proteínas (Smith, 1996), etileno, lípidos, oligoglucanos, quitosanos, sales inorgánicas (García y Pérez, 2003) y jasmonato entre otros (Liang et al. 2006). La síntesis se lleva a cabo en las células sanas que rodean el lugar afectado, de manera que la producción está restringida al lugar de infección (García y Pérez, 2003). Una vez se hace el reconocimiento del factor inductor, la velocidad de transcripción del ARNm de diversas enzimas que participan en la biosíntesis de las fitoalexinas aumenta, dando paso a la aparición de estos compuestos (García y Pérez, 2003). En general el tiempo, la tasa de acumulación y las cantidades relativas de fitoalexinas producidas, son importantes en la resistencia a la invasión por patógenos, y sus actividades son sustancialmente diferentes, sin embargo, no se ha establecido las correlaciones entre los diversos tipos estructurales y su efectividad en el control de la enfermedad (Pedras et al. 2003a). Hay evidencia de que la naturaleza química de estos metabolitos está correlacionada con la familia de plantas que la produce (Pedras y Ahiahonu, 2005). Las fitoalexinas pertenecientes a la familia Brassicaceae, según Takasugi et al. (1986), tienen una única estructura, que está conformada por un anillo indol, que presenta sustituciones en carbono 3 (C-3), así como 
Tabla 2. Producción de fitoalexinas por las especies de la familia Brassicaceae como respuesta a estreses bióticos o abióticos.

\begin{tabular}{|c|c|c|c|}
\hline Especies & Fitoalexinas & $\begin{array}{l}\text { Condición o } \\
\text { patógeno inductor }\end{array}$ & Referencia \\
\hline \multicolumn{4}{|l|}{ Factores bióticos } \\
\hline Arabis lyrata & Camalexina & $\begin{array}{l}\text { Pseudomonas syringae y } \\
\text { Cochliobolus carbonum }\end{array}$ & Pedras et al. 2003b \\
\hline Thlaspi arvense & $\begin{array}{c}\text { Waxalexina } A y \\
\text { arvelexina }\end{array}$ & Leptosphaeria maculans & Pedras et al. 2003b \\
\hline B. napus & $\begin{array}{l}\text { Metoxi-brassinina y } \\
\text { ciclobrassinina }\end{array}$ & L. maculans & Dahiya y Rimmer, 1988 \\
\hline B. oleracea & Brassilexina & L. maculans & Pedras et al. 2006 \\
\hline B. oleraceae & $\begin{array}{c}\text { Caulilexina, ciclo- } \\
\text { brassinina y la } \\
\text { camalexina }\end{array}$ & $\begin{array}{l}\text { Rhizoctonia solani y } \\
\text { Sclerotinia sclerotiorum }\end{array}$ & $\begin{array}{l}\text { Pedras et al. } 2006 \\
\text { Pedras y Aniahonu, } \\
2005\end{array}$ \\
\hline S. alba & Sinalexina, camalexina & Alternaria brassicae & $\begin{array}{l}\text { Pedras y Smith, } 1997 \\
\text { Pedras et al. } 2003 c\end{array}$ \\
\hline Erucastrum gallicum & $\begin{array}{l}\text { indol-3-acetonitrilo, ar- } \\
\text { velexina y } 1 \text {-methoxys- } \\
\text { pirobrassinina }\end{array}$ & Sclerotinia & $\begin{array}{l}\text { Pedras y Ahiahonu, } \\
2004\end{array}$ \\
\hline B. napus & Varias fitoalexinas & $\begin{array}{l}\text { Diferentes cepas de } \\
\text { Albugo candida }\end{array}$ & Pedras et al. 2008 \\
\hline
\end{tabular}

adiciones de átomos de azufre y nitrógeno (Harbone, 1999; Pedras y Ahiahonu, 2005; Ahuja et al. 2012). Adicionalmente, algunas fitoalexinas pertenecientes a esta familia presentan un grupo tiocarbamato (Islam, 2008) o ditiocarbamato, moléculas que han sido empleadas en formulaciones de agroquímicos sintéticos utilizados como fungicidas y herbicidas (Pedras y Ahiahonu, 2005; Glawisching, 2007).El primer reporte de una fitoalexina identificada en la familia Brassicaceae se hizo en 1986 (Takasugi et al, 1986; Islam, 2008), actualmente se tiene conocimiento de 44 tipos de fitoalexinas (Ahuja et al., 2012), dentro de las cuales se encuentran, la waxalexina hallada en Wasabia japonica (Pedras et al. 1999), la cauilexina, aislada de B. oleracea (Pedras et al. 2006), la brassilexina de B. rapa, la camalexina de $A$. thaliana, la ciclobrassinina, la metoxibrassinina, la espiobrassinina, el 3-indolecarbaldehido (Takasugi et al. 1987; Pérez y Pérez, 2004), el brassicanal A (Pedras et al. 2005) y brassitina aislada de Raphanus sativus (Monde et al. 1995).Por último, las fitoalexinas se encuentran en las plantas en bajas concentraciones antes de presentarse algún tipo de 


\begin{tabular}{cccc}
\hline B. juncea & Indol-3-acetonitrilo & Beauveria bassiana & $\begin{array}{c}\text { Pedras y Aniahonu, } \\
\text { 2005 }\end{array}$ \\
\hline Raphanus sativus & Brassinina & $\begin{array}{c}\text { S. sclerotionum, Lep- } \\
\text { tosphaeria biglobosa, } \\
\text { Botrytis cinerea }\end{array}$ & $\begin{array}{c}\text { Pedras et al. 2006 } \\
\text { Pedras et al. 2007Pe- } \\
\text { dras et al. 2011). }\end{array}$ \\
\hline Raphanus sativus & Brassicanal A & $\begin{array}{c}\text { L. maculans (teleomor- } \\
\text { fo) y Phoma lingam } \\
\text { (anamorfo) }\end{array}$ & Pedras y Ahiahonu, \\
2005).
\end{tabular}

estrés, de manera que estas son casi imperceptibles, pero una vez la planta responde a un estimulo, se sintetizan rápidamente (Taiz y Zeiger, 2010). La resistencia por metabolitos, como las fitoalexinas, ocurre cuando la concentración es suficiente para impedir el desarrollo del patógeno (Agrios, 2005), por lo que se podría esperar que la concentración de fitoalexinas adecuada para inhibir el crecimiento de hongos y bacterias sea alta. En este punto no hay acuerdo aún y los reportes son algo contradictorios, ya que se ha reportado que oscila entre $10^{-4}$ y $10^{-6} \mathrm{M}$ (Ebel, 1986), aunque Islam (2008) sostiene que la actividad antifúngica ocurre a concentraciones de entre 0,1 y 0,5 mM.

\section{Fitoalexinas y factores bióticos y abióticos}

Se ha determinado que las fitoalexinas son tóxicas para una amplia gama de microorganismos fitopatógenos tales como hongos y bacterias, así como para herbívoros (Marinelli et al., 1995). Algunas de las especies que se reportan susceptibles son Puccina coronata (Ebel, 1986), Penicillium digitatum (Carbajo, 2004), Phytophthora infestans (Ahuja et al. 2012), 
Botrytis cinerea (Pedras y Ahiahonu, 2005). Posiblemente el mecanismo de acción de estos metabolitos se da en las membranas celulares, pero el modo de acción aún permanece algo confuso, posiblemente consecuencia de la gran variedad de moléculas incluidas en esta denominación (Smith, 1996; Ahuja et al. 2012). Para el caso específico de las fitoalexinas presentes en la familia Brassicaceae se ha detectado que los perfiles tanto cuantitativos como cualitativos difieren, hecho que se asocia a la resistencia que presentan las diferentes especies de la familia contra los distintos patógenos (Tabla 2). Por ejemplo Camelina sativa y Capsella bursa-pastoris muestran resistencia a Alternaria brassicae, mientras que Brassica campestris es menos susceptible comparada con B. campestris y B. napus (Conn et al. 1988). Otros ejemplos se describen en la Tabla 2. Algo que se hace evidente es que muchas de las fitoalexinas exhiben actividad antifúngica contra fitopatógenos importantes a nivel económico, por ejemplo, Botrytis cinerea por su parte ha sido afectado por brassilexina, camalexina y ciclobrassinina según Pedras et al. en 2011. Sin embargo, algunos fitopatógenos pueden presentar enzimas capaces de desintoxicar las fitoanticipinas o fitoalexinas producidas por su hospedero (Van Etten et al. 1995; Pedras y Ahiahonu, 2005).

Tal vez la fitoalexina que más ha sido estudiada es la camalexina, puesto que es sintetizada por A. thaliana, lo cual ha hecho posible establecer más hongos que son susceptibles a este compuesto, dentro de estos se encuentran: Alternaria bassicae, A. brassicola, Botrytis cinerea, Blumeria graminis, Cochliobolus carbonum, Colletotrichum higginsianum, Erysiphe pisi, Golovinomyces orontii, Hyaloperonospora parasítica, Plectosphaerella cucumerina, Puccinia triticina y los oomycetos Phytophthora brassicae, P. infestans, P. porri, Pythium sylvaticum, entre otros (Ahuja et al. 2012). El sistema de defensa de respuesta inducida es activado cuando la planta se expone a diferentes tipos de estrés biótico (Bruce y Pickett, 2007). La actividad de los glucosilonatos así como de sus productos contra varios microorganismos ha sido reportada (Jahagir et al. 2009). El primer reporte de actividad antibacteriana fue hecho en 1954 por Kjær y Conti, y para el caso de la actividad anticancerígena el primer reporte se tiene desde 1967 con el trabajo realizado por Drobnica et al. (1967) (Fahey et al. 1997; Fahey y Stephenson, 1999).

Los factores abióticos también provocan respuestas en algunas especies de Brassicaceae, produciendo diferentes fitoalexinas (Tabla 2). El cloruro de cobre ha mostrado su capacidad para inducir efectivamente la producción de fitoalexinas en varias especies de Brassicaceae (Jahangir et al. 2009) y se ha reportado también que la concentración de spirobrassinina fue cuatro veces mayor $(167 \mathrm{nmol} /$ gramo de peso fresco) a la que se observa en interacciones bióticas y abióticas, cuando se usaba la mayor concentración de cloruro de cobre, después de dos días de exposición (Pedras et al. 2008). Este efecto se ha probado en hojas de Brassicaceae como canola y colza (B. rapa), al acumular spirobrassinina, ciclobrassinina, rutalexina, rapalexina $A$ y $B$, brassinina, brassilexina y brassianal C, aparte de fitoalexinas como, indolyl-3-acetonitrilo, caulilexina $\mathrm{C}$ y arvelexina, luego de haber sido tratadas con cloruro de cobre (Pedras et al. 2003b). La luz UV, es otro de los factores ambientales importantes en la inducción de fitoalexinas Algunos ejemplos específicos se muestran en la Tabla 2.

\section{Glucosilonatos}

Los glucosinolatos son metabolitos secundarios derivados de aminoácidos (Fahey et al. 1999; Jahangir et al. 2009; Vig et al. 2009). Estos metabolitos han sido ampliamente estudiados junto con el contenido de aceites y ácidos grasos de las semillas, producidos por las Brassicaceae, principalmente por su constitución química y contenido (Anjum et al. 2011; Warwick, 2011). Estos metabolitos y sus productos de hidrólisis son los que confieren los olores y sabores característicos a las Brassicaceae. 
Adicionalmente son importantes en la defensa química de las plantas frente a patógenos, herbívoros y algunas arvenses (Clauss et al. 2006; Anjum et al. 2011; Warwick, 2011). Han sido reportados más de 96 glucosinolatos en la familia Brassicaceae, de los cuales la mayoría son únicos para ciertas especies y géneros (Anjum et al. 2011). Sin embargo los glucosinolatos no están limitados a las brassicáceas, de hecho se han reportado en al menos 500 especies de angiospermas dicotiledóneas con uno o más de los 120 glucosinolatos conocidos (Fahey et al. 1999). Todas las Brassicaceae son capaces de sintetizar glucosinolatos (Angelini et al., 1997; Jahangir et al. 2009; Warwick, 2011). Se han realizado muchos estudios sobre los estos metabolitos secundarios presentes en especies silvestres, tales como Brassicae oleracea, Cakile spp., Capsiella bursa-pastoris, Diplotaxis tenuifolia, Elysium allionii, E. cheiri, E. vesicaria, E. vesicaria sub sp sativa, $H$. matronalis, $L$. fendleri, $L$. marítima, Lepidium peruvianum, Matthiola longipetala (Warwick, 2011). Muchas de estas plantas tienen potencial para ser cultivables con el fin de obtener productos farmacéuticos, por ejemplo, el sulforafano, el cual es efectivo contra patógenos como bacterias, levaduras, hongos, micoplasmas, protozoos, nematodos y virus (Warwick, 2011).

Los glucosinolatos son inducidos por diversos factores, dentro de los cuales se encuentran heridas o el ataque de patógenos (Butcher et al. 1974), insectos y herbívoros (Fahey et al. 1999), los reguladores de crecimiento (Bodnaryk, 1994; Bodnaryk y Yoshihara, 1995), el estrés salino (Bones y Rossiter, 2006), diversos factores ambientales (Booth y Walker, 1992; Fahey y Stephenson, 1999), la densidad del cultivo (Haramoto y Gallandt, 2004) o algunas moléculas de señalización de las plantas, incluyendo el tratamiento con ácido salicílico, ácido jasmónico y metil jasmonato (Jahangir et al. 2009). Seguido al daño del tejido, los glucosinolatos inician el proceso de hidrólisis. Este proceso es catalizado por la enzima mirosinasa que hidroliza los glucosinolatos a agliconas inestables, lo cual lleva a la producción de una variedad de productos que abarcan isotiocianatos, tiocianatos y nitrilos. La naturaleza de estos depende de las condiciones de hidrólisis y del glucosinolato en particular (Manici et al. 2000; Pérez y Pérez, 2004; Jahangir et al. 2009; Vig et al., 2009). Los más numerosos son aquellos que contienen cadenas de carbono lineales o ramificadas, muchos tienen dobles enlaces, grupos hidroxilo o carbonilo o enlaces de azufre en diferentes estados de oxidación y un tercio del total de glucosinolatos contiene un átomo de azufre (Fahey et al. 1999). La biosíntesis de los glucosilonatos tanto alifáticos como indólicos se divide en tres pasos que son: el reclutamiento de los aminoácidos precursores y la elongación de la cadena lateral, posteriormente la formación del núcleo estructural de los glucosinolatos y, finalmente, se lleva a cabo la modificación de la cadena lateral (Chan et al. 2010; Sønderby et al. 2010; Björkman et al. 2011).

\section{Sin embargo los glucosinolatos no están limitados a las} brassicáceas, de hecho se han reportado en al menos 500 especies de angiospermas dicotiledóneas con uno o más de los 120 glucosinolatos conocidos (Fahey et al. 1999). 


\section{La concentración de glucosinolatos varía dependiendo de la} especie, el órgano y el estado en el cual se encuentre la planta (Malik et al. 2010).

Los glucosinolatos son agrupados en clases según las similitudes estructurales que presentan (Vig et al. 2009), y entre los más estudiados están los alifáticos, aromáticos, heterocíclicos y metiltioalquilicos, principalmente encontrados en los cultivos pertenecientes al género Brassica (sinigrina, gluconasturtiin y gluconapin, entre otros) (Oerlemans et al. 2006).

En algunos tejidos de Brassica, el contenido de glucosinolatos reportado es de $1 \%$ en peso seco, sin embargo, en las semillas puede llegar a ser del 10\% en algunas plantas, lo cual representa la mitad del contenido de azufre en semillas (Josefsson, 1970). Muchas especies contienen un número limitado de glucosinolatos, menos de una docena, aunque al menos 23 diferentes glucosinolatos se han identificado en Arabidopsis thaliana (Fahey et al. 1999). La distribución de glucosinolatos ha sido estudiada en varios órganos de las plantas, tanto cuantitativamente como cualitativamente, mostrando diferencias entre las raíces, hojas, tallos y semillas (Fahey et al. 1999). Por ejemplo, las semillas o brotes jóvenes de bróccoli (Brassica oleracea var. italica) puede contener entre 70 y $100 \mu \mathrm{mol}$ totales de glucosinolatos por gramo de tejido fresco, con $<1 \%$ de indol-glucosinolatos y el balance consiste casi en su totalidad de glucosinolatos alifáticos, glucoraphanina, glucoerucina y glucoiberina (Fahey et al. 1997).

La concentración de glucosinolatos varía dependiendo de la especie, el órgano y el estado en el cual se encuentre la planta (Malik et al. 2010). Por ejemplo en la especie Raphanus sativus se han reportado glucosinolatos indólicos como 3-indolmetil glucosinolato, 1-metoxi-3-indolmetoxi glucosinolato y 4-hidroxi-3-indolmetil glucosinolato, presentándose el primero en las hojas, el segundo y el tercero en diferentes órganos de las plantas, aunque el último también se encuentra en las semillas con un contenido de 37 y 87 mmol/g de semilla (Changdai, 1984; Sang et al., 1984; Pérez y Pérez, 2004). En las hojas de las plantas de esta especie también se han encontrado glucosinolatos alifáticos y aromáticos tales como, 4-metilpentilo isotiocianato, el bencil isotiocianato, el 4-(metiltio)-3-butenilo isotiocianato, el 4-(metiltio) butil isotiocianato, el 5-(metiltio)-4-pentenonitrilo, el 2-feniletilo isotiocianato, el benzenopropanonitril y el 4-(metiltio)-3-butenil isotiocianato (Wei et al. 2002). Los cultivos, en estado reproductivo, pueden alcanzar entre 1 y $4 \mathrm{\mu mol}$ de glucosinolatos totales por gramo de peso fresco, presentando glucosinolatos de naturaleza alifática e indólica, en concentraciones que pueden llegar a ser similares (Fahey et al. 1997; Fahey y Stephenson, 1999). La edad de la planta es uno de los determinantes importantes en la composición de glucosinolatos a nivel cuantitativo y cualitativo (Fahey et al. 1999), siendo los tejidos jóvenes aquellos que tienen la mayor cantidad de glucosinolatos (Ludvick-Müller et al. 2000; Blažević y Mastelić, 2009).Para el caso de Raphanus raphanistrum se han reportado glucosinolatos como glucoiberina, glucorafanina, gluconapina, glucobrassicina, 
glucosinalbina, gluconasturtina, progoitrina, glucoerucina, glucorafenina y glucotropaeolina (Malik et al. 2008), aunque los tres últimos conforman más del $90 \%$ para esta especie, con contenidos que varían entre las etapas de desarrollo, por ejemplo en los cotiledones hay $5.70 \mathrm{~mol} / \mathrm{planta}$, en floración es de $1942.2 \mathrm{~mol} /$ planta y en estado de silicua (frutos) este contenido disminuye un 35\% (Malik et al. 2010). Aunque también hay reportes de altas concentraciones en los órganos reproductivos, como en las inflorescencias (25-30 $\mathrm{mmol} / \mathrm{g})$, en las silicuas $(15-25 \mu \mathrm{mol} / \mathrm{g})$ y en las semillas (63 $\mu \mathrm{mol} / \mathrm{g}$ ) (Brown et al. 2003). En otros órganos, como la raíz, se encuentra alrededor de 5,3 y $12,92 \%$ del contenido de glucosinolatos, mientras que en las flores hay $11,83 \%$ y en la etapa final, es decir cuando se presentan los frutos, glucosinolatos como la glucoiberina está presente en todos los órganos de la planta (Malik et al. 2010).

\section{Efecto de las moléculas de señalización en la producción de glucosinolatos}

En las Brassicaceae las moléculas de señalización pueden cambiar el perfil de glucosinolatos. En el caso de $A$. thaliana, las respuestas a diferentes condiciones de estrés son coordinadas por la interacción de varios sistemas de señalización, entre las cuales se incluyen las vías mediadas por jasmonato, ácido salicílico y etileno (Mewis et al, 2005; Jahangir et al. 2009). Se ha demostrado que plantas de B. napus expuestas a metil jasmonato (MeJA) acumulan glucosinolatos de naturaleza indólica en sus hojas y la cantidad de estos depende de la concentración de MeJA aplicado (Dougthy et al. 1995), en hojas de $B$. rapa, un incremento en los niveles de glucosinolatos fue observado después de la inducción con MeJA (Liang et al. 2006). Ludwig-Müller et al. (1997), trabajando con variedades resistentes y susceptibles de B. campestris expuestas a ácido salicílico y jasmonato, encontraron un incremento en la cantidad de glucosinolatos totales, sin embargo, la respuesta era dependiente del tipo de tratamiento aplicado. En este caso el jasmonato indujo la producción de glucosinolatos indólicos sólo en las hojas, mientras que con ácido salicílico los glucosinolatos se presentaron tanto en hojas como en raíces (Ludwig-Müller et al. 1997). Un par de ejemplos adicionales, son un estudio realizado para determinar el contenido de glucosinolatos en hojas y cotiledones de $B$. napus, $B$. rapa y $B$. juncea, se encontró que el contenido de glucobrassicina y 4-hidroxiglucobrassicina se incrementaba hasta 20 veces después de haber tratado dichos órganos con jasmonato y metil jasmonato (Bodnaryk, 1994), mientras que Mollers et al. en 1999 usando B. napus tratadas con ácido abscísico reportaron la producción de niveles bajos de glucosinolatos indólicos. En conclusión, la regulación por moléculas de señalización parece ser un fenómeno quizás complicado por la transducción de señales ambientales.

\section{Efecto de la herbivoría en la producción de glucosinolatos}

Los niveles de glucosinolatos incrementan, y su composición puede ser alterada, en respuesta a un ataque de herbivoros en varias especies de Brassicaceae (Bruce y Pickett, 2007). Evidencia de esto fue el estudio realizado con dos especies silvestres de Brassica, B. nigra y B. oleracea, que fueron infestadas con larvas de Delia radicum, la respuesta sistemática difiere entre especies. Para el caso de B. nigra los niveles de glucosinolatos incrementaron constantemente en el periodo de crecimiento, casi duplicando la concentración inicial después de 14 días de infestación. En B. oleracea no hubo cambio significativo en los niveles de glucosinolatos, comparado con los tratamientos control (Van Dam y Raaijmakers, 2006). Una respuesta similar fue observada en $A$. thaliana en respuesta a Myzus persicae (Jahagir et al. 2009), entre otros casos en los que se han reportado por varios autores citados por Jahangir et al. (2009). Cole (1997) encontró en hojas de B. oleracea var. capita 
cv offenham compacta una concentración inusual del glucosinolato 2-hidroxi-3-butenil, lo cual posiblemente hace que dicha variedad sea más susceptible a Brevicoryne brassicae, comparada con otras B. oleracea examinadas. Esto le permitió llegar a la conclusión de que el incremento en la producción de 4-pentenilglucosinolato, con una reducción proporcional en los glucosilonatos 2-hidroxi-3-butenil y 2-propenil, puede proporcionar a los cultivos de Brassica resistencia parcial a B. brassicae. Esto hace parte de la evidencia sobre la influencia que tienen las estructuras y los niveles de glucosinolatos, en la interacción entre planta-hospedero para herbívoros generalistas y especialistas (Jahangir et al. 2009).

\section{Efecto de los patógenos en la producción de glucosinolatos}

Los patosistemas también son afectados por la presencia de gucosinolatos en las plantas, determinando en algunos casos la posibilidad de su establecimiento o no. Sin embargo, como puede verse más adelante, la respuesta no es necesariamente consistente o universal.El contenido total de glucosinolatos presente en una variedad de repollo resistente y otra susceptible a la enfermedad causada por Plasmodiophora brassicae, reveló que la cantidad de estos metabolitos variaba significativamente entre las variedades, mientras que la variedad susceptible tenía un alto contenido de glucosinolatos alifáticos, la resistente mostró un alto contenido de glucosinolatos aromáticos (Ludwig-Müller et al. 1997). En cuanto a la actividad contra hongos fitopatógenos, ya en 1967 Drobnica et al. demostraron la efectividad de los isotiocianatos contra cepas de Aspergillus niger, Penicillium cyclopium y Rhizopus oryzae. Por su parte, Mari et al. (1993) encontraron que los glucosinolatos son inactivos contra patógenos tales como B. cinerea, Monilinia laxa, Mucor pririformis, Penicillium expansum y Rhizopus stolonifer, mientras que los isotiocianatos resultan tener actividad biocida contra estas mismas cepas, aunque con intensidad y especificidad variable. Este tipo de actividad también se demostró en contra de Gaeumannomyces graminis, dónde la curva de dosis respuesta de los isotiocianatos mostró inhibición del hongo desde concentraciones bajas $\left(10^{-1} \mathrm{M} \mathrm{L}^{-1}\right)$, con un porcentaje de inhibición del 60-80\% con respecto al control (Angus et al. 1994). En 1996, Doughty et al. describieron el catabolismo de los glucosinolatos durante la infección y subsecuente liberación de isotiocianatos, junto con dimetil disulfuro, dimetil trisulfuro y 4-oxisforona, al inocular semillas de $B$. rapa con Alternaria brassicae (Jahangir et al. 2009). Los isotiocianatos como 2-propenil, etil, butil, feniletil, bencil o fenil isotiocianato, han reportado tener actividad contra Fusarium oxysporum (Smolinska et al. 2003) y F. graminearum (Kirkegaard y Sarwar, 1998) aunque el efecto sobre estos es fungistático. Otros isotiocianatos como 2-feniletil y alil isotiocianato inhibieron Alternaria alternata (Troncoso et al.

\section{Los patosistemas también son afectados por la presencia de gucosinolatos en las plantas, determinando en algunos casos la posibilidad de su establecimiento o no.}


2005). Con respecto a la actividad antibacteriana se ha reportado eficacia contra $P$. fluorescens, S. albus (Johns et al. 1982), así como contra B. subtilis, B. stearothermophilus, S. thermoviolaceus y E. coli (Brabban y Edwards, 1995; Hashem y Saleh, 1999).

\section{Efecto de la nutrición mineral en la producción de glucosinolatos}

El uso de fertilizantes, con bajo contenido de nitrógeno y alto de azufre, favorece un incremento en la acumulación de glucosinolatos indólicos, alifáticos y aromáticos (Jahangir et al. 2009). Por ejemplo, el uso de un fertilizante de azufre incrementó la producción de glucosilonatos, gluconaparina, sinigrina y protoitrina (Kaur et al. 1990). En B. rapa, el total de glucosinolatos incrementó en respuesta a la disponibilidad de azufre (Kim et al. 2002) así como en B. oleracea (Kopsell et al. 2003). Por otra parte, tres cultivares de brócoli mostraron un incremento en el contenido total de glucosinolatos, al iniciar el desarrollo de las inflorescencias, seguido por la rápida disminución en función de la fertilización con azufre (Vallejo et al. 2003). Por otra parte, la presencia excesiva de selenio afectó el contenido de los glucosinolatos en general y en particular de sulforafano, el cual disminuyó (Robbins et al. 2005). También en brócoli se mostró que el estrés salino incrementa el contenido de glucosinolatos, lo cual indica un posible papel de estas moléculas en la respuesta a dicho estrés (Lopez-Berenguer et al. 2008). Aunque también se han encontrado excepciones, como es el caso de B. rapa en donde el estrés por cadmio no produjo cambios en la producción de glucosinolatos (Siemens et al. 2002).

\section{Efecto de la temperatura y la radiación en la producción de glucosinolatos}

Existe una relación entre la temperatura, la radiación y el contenido de glucosinolatos, aunque la síntesis de cada glucosinolato se ve afectada de manera diferente por cada uno de estos factores (Schonhof et al. 2007; Volden et al. 2008). La concentración de glucosinolatos en canola (B. napus) se incrementa cuando esta planta es sometida a un estrés por temperatura, de $40^{\circ} \mathrm{C}$, durante 15 días en etapa de crecimiento (Aksouh et al. 2001). Para temperaturas inferiores a $12^{\circ} \mathrm{C}$, las plantas experimentan una disminución del $29 \%$ de glucosinolatos en todos los tejidos de esta planta (Pereira et al. 2002). La variación estacional influye en el contenido de glucosinolatos alifáticos, indol, y aromáticos en tres variedades de B. oleracea (Cartea et al. 2008). El mismo efecto se observó en el brócoli, al incrementar el contenido de glucosinolatos alifáticos (en especial de glucorafanina) cuando se mantienen a temperaturas medias diarias entre 7 y $13^{\circ} \mathrm{C}$ en combinación con radiación media diaria de 10 a $13 \mathrm{~mol}$ m-2 día-1 (Schonhof et al. 2007). El efecto de la radiación puede depender de la especie, como en el caso de Nasturtium officinale y S. alba, en la que se habían identificado diferentes glucosinolatos alifáticos e indólicos. La concentración de estos se ve influenciada por el tratamiento con UV más en $N$. officinale que en S. alba (Reifenrath y Muller, 2007). Así mismo cuando las plantas son expuestas a un fotoperiodo mayor a 14 horas de luz ocurre un incremento en estos metabolitos secundarios (Charrom y Sams, 2004).

\section{Efecto del pH, el agua y el $\mathrm{CO}_{2}$ en la producción de glucosinolatos}

El pH del suelo es otro factor determinante de la cantidad de glucosinolatos que hay en la planta, se ha demostrado que la degradación de la mirosinasa es dependiente de esta variable, además se sabe que los isotiocinatos se producen en $\mathrm{pH}$ neutro (Bones y Rossiter, 2006). Por su parte, el agua es otro factor influyente puesto que aquellas plantas con poco riego, aumentan el contenido de glucosinolatos (Radovich et al. 2005; Zhang et al. 2008). Al igual que los otros factores, el $\mathrm{CO}_{2}$ también es importante, debido a que las plantas que están expuestas a altas concentraciones de este gas presentan un aumento en el contenido de 
glucorafanina y glucoiberina, mientras que los glucosinolatos indólicos disminuyen (Karowe et al. 1997).

\section{Efecto de las condiciones de almacenamiento después de la cosecha en la producción de glucosinolatos}

La ruptura física de las plantas en la postcosecha (masticar, picar, mezclar, hacer jugo, cocción, congelación/descongelación, altas temperaturas) conduce a la pérdida de la compartimentalización celular. Esta situación favorece el contacto de los glucosinolatos con la enzima mirosinasa de donde resulta la formación de isotiocianatos (Jahangir et al. 2009), nitrilos, tiocianatos, epitionitrilos y oxazolidinas (Bones y Rossiter, 2006). Cuando las plantas se almacenan a temperatura ambiente (12$22^{\circ} \mathrm{C}$ ), no hay pérdida significativa en el contenido de estos metabolitos secundarios, pero el contenido disminuye en las variedades hortícolas como brócoli, coliflor, coles de bruselas y repollo verde, cuando son almacenados en un refrigerador doméstico $\left(4-8^{\circ} \mathrm{C}\right)$ durante 7 días. Algunos de estos metabolitos son gluicoberina, glucorafanina y glucoalisina, los cuales disminuyen más que la sinigrina, gluconapina y progoitrina (Song y Thornalley, 2007). Los glucosinolatos son los compuestos más afectados en las hojas de Eruca vesicaria, al dejarlas expuestas al aire, el contenido se redujo entre un 4 y 33\%, mientras que cuando se expusieron a bajas concentraciones de $\mathrm{O}_{2}$ y altas de $\mathrm{CO}_{2}$ la disminución fue entre 60 y 100\% (Martinez-Sanchez et al. 2006), sin embargo, el contenido de glucorafanin y glucoiberin aumentó (Karowe et al. 1997). El almacenamiento de vegetales a $-85^{\circ} \mathrm{C}$ puede causar pérdidas significativas de glucosinolatos debido a la ruptura de congelación/descongelación de las células vegetales dando lugar a una conversión enzimática de glucosinolatos e isotiocianatos durante la descongelación (Song y Thornalley, 2007). También una disminución significativa se detectó en los vegetales del género Brassica en 4 y $20^{\circ} \mathrm{C}$ (Winkler et al. 2007). Por otro lado, los glucosinolatos indólicos y alifáticos en brócoli incrementan durante un periodo de almacenamiento de 7 días a $7-13^{\circ} \mathrm{C}$ (Schonhof et al. 2007).

\section{CONCLUSIONES}

La familia Brassicaceae posee muchas características biológicas interesantes, no solo por su diversidad, plasticidad e historia evolutiva, si no también por su potencial de uso en la alimentación y en la obtención de substancias útiles en otros ámbitos.

Este último aspecto descansa en su metabolismo secundario, el cual ha sido estudiado de manera más o menos intensiva en particular en lo referente a la producción de los glucosinolatos. Sin embargo, otros metabolitos y su regulación han sido también considerados, pero falta lo que parece ser un largo camino por recorrer en esta área.

Fue parte del interés en la preparación de esta revisión llamar la atención sobre el tema y estimular investigaciones en el área.

\section{AGRADECIMIENTOS}

A la Dra. Silvia Restrepo por su lectura crítica y sus acertadas observaciones que enriquecieron la estructura de este trabajo. Este trabajo es producto del proyecto CIAS 940, financiado por la Vicerrectoría de Investigaciones de la Universidad Militar Nueva Granada. 


\section{BIBLIOGRAFÍA}

1. Agrios GN. 2005. Plant Pathology. Quinta edición. Elsevier. Burlington. 838 p.

2. Ahuja I, Kissen R, Bones AM. 2012. Phytoalexins in defense against pathogens. Trends plant sci 17: 73-90.

3. Aksouh NM, Jacobs BC, Stoddard FL, Mailer RJ. 2001. Response of canola to different heat stresses. Aust J Agr Res 52(8): 817-824.

4. Anjum NA, Gill SS, Ahmad I, Pacheco M, Duarte AC, Umar S, Khan NA, Pereira ME. 2011. The Plant Family Brassicaceae: An introduction. pp 1-33. En: Anjum NA, Ahmad I, Pereira ME, Duarte AC, Umar S, Khan NA. (Eds.), The Plant Family Brassicaceae. Springer, The Netherlands.

5. Angelini LG, Moscheni E, Colonna G, Belloni P, Bonari E. 1997. Variation in agronomic characteristics and seed oil composition of new oilseed crops in central Italy. Ind Crop Prod 6: 313-323.

6. Angus JF, Gardner PA, Kirkegaard JA, Desmarchelier JM. 1994. Biofumigation: Isothiocyanates released from Brassica roots inhibit growth of the take-all fungus. Plant Soil 162:107- 112.

7. Appel O, Al-Shehbaz IA. 2003. Cruciferae. $\mathrm{P}$ 75-174. En: Kubitzki K, Bayer C (Eds.). The families and genera of vascular plants. Springer, New York.

8. Arras G, Sanna P. 1999. Resistance of citrus fruits to Penicillium italicum. Crop Prot 64: 527-530.

9. Arrieta JM. 2000. Manejo integrado de malezas en el cultivo de papa. Manual para el cultivo de la papa en Colombia 1: 144-159.

10. Blažević I, Mastelić J. 2009. Glucosinolate degradation products and other bound and free volatiles in the leaves and roots of radish (Raphanus sativus L.). Food Chem 113: 96-102.
11. Björkman M, Klingen I, Birch ANE, Bones AM, Bruce TJA, Johansen TJ, Meadow R, Mølmann J, Seljasen R, Smart LE, Stewart D. 2011. Phytochemicals of Brassicaceae in plant protection and human health - Influences of climate, environment and agronomic practice. Phytochem 72: 538-556.

12. Bodnaryk RP. 1994. Potent effect of jasmonates on índole glucosinolates in oilseed rape and mustard. Phytochem 35 (2): 301-305.

13. Bodnaryk, R, Yoshihara T. 1995. Structure - activity relationships of cyclopentane analogs of jasmonic acid for induced responses of canola seedling Brassica napus L. J Chem Ecol 21 (11): 1735 - 1743.

14. Bones AM, Rossiter JT. 2006. The enzymatic and chemically induced decomposition of glucosinolates. Phytochem 67: 1053-1067.

15. Booth EJ, Walker KC. 1992. The effect of site and foliar sulfuro on oilseed rape: comparison of sulfur responsive and non-responsive seasons. Phyton-Int J Exp Bot 32 (3): 9-13.

16. Brabban AD, Edwards C. 1995. The effect of glucosinolates and their hydrolisis products on microbial growth. J Appl Bacteriol 79: 171-177.

17. Brown PD, Tokuhisa JG, Reichelt M, Gershenzon J. 2003. Variation of glucosinolate accumulation among different organs and developmental stages of Arabidopsis thaliana. Phytochem 62: 471-481.

18. Bruce TJA, Pickett JA. 2007. Plant defence signalling induced by biotic attacks. Curr Op Plant Biol 10: 387-392.

19. Butcher DN, El-Tigani S, Ingram DS. 1974. The role of indole glucosinolates in the club root disease of the Cruciferae. Physiol Plant Pathol 4: $127-140$.

20. Carbajo MS. 2004. Sistemas alternativos a los fungicidas químicos para el control de 
Penicillium digitatum (Pers.) Sacc. en limón. Universidad Nacional de Tucumán. Tesis.

21. Cartea ME, Velasco P, Obregón S, Padilla G, de Haro A. 2008. Seasonal variation in glucosinolate content in Brassica oleracea crops grown in northwestern Spain. Phytochem 69: 403-410.

22. Chan EKF, Rowe HC, Kliebenstein DJ. 2010. Understanding the evolution of defense metabolites in Arabidopsis thaliana using genome-wide association mapping. Genetics 185: 991-1007.

23. Changdai W. 1984 Studies on chemical constituents in Radish (Raphanus sativus L) Seed II. Shaanxi Xinyiyao 13: 54-55.

24. Charron CS, Sams CE. 2004. Glucosinolate content and myrosinase activity in rapid cycling Brassica oleracea grown in a controlled environment. J Am Soc Hortic Sci 129: 321-330.

25. Choudhary DK, Prakash A, Johri BN. 2007. Induced Systemic Resistance (ISR) in plants: mechanism of action. Ind J Microbiol 47:289-297.

26. Clauss MJ, Dietel S, Schubert G, Mitchell-Olds T. 2006. Glucosinolate and Tricome defense in a natural Arabidopsis lyrata population. J Chem Ecol 32: 2351-2373.

27. Cole RA. 1997. The relative importance of glucosinolates and amino acids to the development of two aphids pests Brevicoryne brassicae and Myzus persicae on wild and cultivated brassica species. Entomol Exp Appl 85: 121-133.

28. Conn KI, Tewari JP, Dahiya JS. 1988. Resistance to Alternaria brassicae and phytoalexin-elicitation in rapeseed and other crucifers. Plant Sci 56: 21-25.

29. Dahiya JS, Rimmer SR. 1988. Phytoalexin accumulation in tissues of Brassica napus inoculated with Leptosphaeria maculans. Phytochem 27(10): 3105-3107.

30. Dhaubhadel S, Chaudhary S, Dobinson KF, Krishna P. 1999. Treatment with 24-epibrassinolide, a brassinosteroid, increases the basic thermotolerance of Brassica napus and tomate seedlings. Plant Mol Biol 40: 333-342.

31. Doughty KJ, Kiddle GA, Pye J, Wallsgrove RM, Pickett JA. 1995. Selective induction of glucosinolates in oilseed rape leaves by methyl jasmonate. Phytochem 38(2): 347-350.

32. Drobnica $L$, Zemanová $M$, Nemec $P$, Antoš $K$, Kristián P, Štullerová A, Knoppová V, Nemec P. 1967. Antifungal activity of Isothiocyanates and related compounds. Appl Microbiol 15 (4): 701-709.

33. Ebel J. 1986. Phytoalexin synthesis: the biochemical analysis of the induction process. Ann Rev Phytopathol 24: 235-264.

34. Erickson DB, Bassin P. 1990. Rapeseed and crambe: alternative crops with potential industrial uses. Bull Kansas University Agricultural Experiment Station and Cooperative Extension Service 656: 1-33.

35. Facciola S. 1990. Cornucopia- a source book of edible plants.. Kampong Publications, Vista, CA. $677 \mathrm{p}$.

36. Fahey JW, Zhang Y, Talalay P. 1997. Broccoli sprouts: An exceptionally rich source of inducers of enzymes that protect against chemical carcinogens. P Natl Acad Sci USA 94: 10367-10372.

37. Fahey JW, Stephenson KK. 1999. Cancer chemoprotective effects of cruciferous vegetables. Am Soc Hortic Sci 34 (7): 1159-1163.

38. Franzke A, Lysak M, Al-Shehbaz IA, Koch MA, Mummenhoff K. 2011. Cabbage family affairs: the evolutionary history of Brassicaceae. Trends Plant Sci16(2):108-116.

39. Fuentes CL, Romero CE. 1991. Una visión del problema de las malezas en Colombia. Agron Colomb 8(2): 364-378.

40. García R, Pérez L. 2003. Phytoalexins: a plant defense mechanism. Rev Chapingo Ser Cie 9: $5-10$. 
41. Gitz DC, Liu L, McClure JW. 1998. Phenolic metabolism, growth, and UV-B tolerance in phenylalanine ammonia-lyase-inhibed red cabbage seedlings. Phytochem 49(2): 377-386.

42. Glawischnig E. 2007. Molecules of interest camalexin. Phytochem 68: 401-407.

43. Hammerschmidt R. 1999. Phytoalexins: What have we learned after 60 years? Ann Rev Phytopathol 37: 285-306.

44. Haramoto ER, Gallandt ER. 2004. Brassica cover cropping for weed management: a review. Renew Agr Food Syst 19: 187-198.

45. Harborne J.B. 1999. The comparative biochemistry of phytoalexin induction in plants. Biochem Syst Ecol 27: 335-367.

46. Hashem FA, Saleh MM. 1999. Antimicrobial components of some Cruciferae plants (Diplotaxis harra Forsk and Erucaria microcarpa Boiss). Phytother Res 13: 329-332.

47. Heil M, Bostock R. 2002. Induced Systemic Resistance (ISR) against pathogens in the context of induced plant defences. Ann Bot 89:503-512

48. Huang BQ, Lou P, Li YW. 1999. Domestication and cultivation of Orychophragmus violaceus as a new oil crop in China. Cruciferae Newsl Eucarpia 21:13-14.

49. Islam MS. 2008. Biotransformation of the phytoalexins brassinin, brassilexin and camalexin by Alternaria brassicicola. M.Sc.Thesis. University of Saskatchewan, Canada.

50. Jahangir M, Kim HK, Choi YH, Verpoorte R. 2008. Metabolomic response of Brassica rapa submitted to pre-harvest bacterial contamination. Food Chem 107: 362-368.

51. Jahangir M, Abdel-Farid IB, Kim HK, Choi YH, Verpoorte R. 2009. Healthy and unhealthy plants: The effect of stress on the metabolism of Brassicaceae. Environ Exp Bot 67(1): 23-33.

52. Johns T, Kitts WD, Newsome F, Towers HN. 1982. Anti-reproductive and other medicinal effects of Tropaeolum tuberosum. J Ethnopharmacol 5: 149-161.

53. JosefssonE. 1970. Pattern, contentand biosynthesis of glucosinolates in some cultivated Cruciferae. Svalöf, Swedish Seed Association, Sweden.

54. Kaur S, Gupta SK, Sukhija PS, Munshi SK. 1990. Accumulation of glucosinolates in developing mustard (Brassica juncea L.) seeds in response to sulphur applications. Plant Sci 66: 181-184.

55. Karowe DN, Seimens DH, Mitchell-Olds T. 1997. Species-specific response of glucosinolate content to elevated atmospheric $\mathrm{CO}_{2}$. J Chem Ecol 23: 2569-2582.

56. Kim SJ, Matsuo T, Watanabe M. 2002. Effect of nitrogen and sulphur application on the glucosinolate content in vegetable turnip rape (Brassica rapa L.). Soil Sci Plant Nutr 48 (1): 43-49.

57. Kirkegaard JA, Sarwar M. 1998. Biofumigation potential of brassicas. Plant Soil Environ 201: 71-79.

58. Kopsell DE, Kopsell DA, Randle WM, Coolong TW. 2003. Kale carotenoids remain stable while flavor compounds respond to changes in sulfur fertility. J Agr Food Chem 51(18): 5319-5325.

59. Krishna P. 2003. Brassinosteroid-Mediated Stress Responses. J Plant Growth Regul 22: 289-297.

60. Kugel RK, Falk KC. 2006. Agronomic and seed quality evaluation of Camelina sativa in western Canada. Can J Plant Sci 86: 1047-1058.

61. Liang $Y$, Choi $Y H$, Kim HK, Linthorst HJM, Verpoorte R. 2006. Metabolomic analysis of methyl jasmonate treated Brassica rapa leaves by 2-dimensional NMR spectroscopy. Phytochem 67: 2503-2511.

62. Lichtenthaler HK. 1999. The 1-deoxy-D-xylulose-5-phosphate pathway of isoprenoid biosynthesis in plants. Annu Rev Plant Phys 50: 47-65.

63. Lopez-Berenguer C, Matínez-Ballesta MC, García-Viguera C, Carvajal M. 2008. Leaf water 
balance mediated by aquaporins under salt stress and associated glucosinolate synthesis in broccoli. Plant Sci 174: 321-328.

64. Lo Scalzo R, Genna A, Branca F, Chedin M, Chassaigne H. 2008. Anthocyanin composition of cauliflower (Brassica oleracea L. var. botrytis) and cabbage (B. oleracea L. var. capitata) and its stability in relation to thermal treatments. Food Chem 107(1): 136-144.

65. Ludwig-Müller J, Schubert B, Pieper K, Ihmig S, Hilgenberg W. 1997. Glucosinolate content in susceptible and resistant Chinese cabbage varieties during development of clubroot disease. Phytochem 44(3): 407-414.

66. Ludvick-Müller J, Krishna P, Forreiter C. 2000. A glucosinolate mutant of Arabidopsis is thermosensitive and defective in cytosolic Hsp90 expression after heat stress. Plant Physol 123: 949-958.

67. Malik MS, Norsworthy JK, Culpepper AS, Riley MB, Bridges Jr. W. 2008 Use of wild radish (Raphanus raphanistrum) and rye cover crops for weed suppression in sweet corn. Weed Sci 56 (4): 588-595.

68. Malik MS, Riley MB, Norsworthy JK, Bridges Jr W. 2010. Glucosinolate profile variation of growth stages of wild radish (Raphanus raphanistrum). J Agr Food Chem 58: 3309-3315.

69. Manici LM, Lazzeri L, Baruzzi G, Leoni O, GaIletti S, Palmieri S. 2000. Suppressive activity of some glucosinolate enzyme degradation products on Pythium irregulare and Rhizoctonia solani in sterile soil. Pest Manag Sci 56: 921-926.

70. Mari M, Oiri R, Leoni O, Marchi A. 1993. In vitro activity of glucosinolate-derived isothiocyanates against postharvest fruit pathogens. Ann Appl Biol 123: 155 - 164.

71. Marinelli FU, Zanelli R. 1995. Toxicity of 6-methoxymellein and 6-hydroxymellein to the producing carrot cells. Phytochem 42: 641-643.
72. Martinez-Sanchez A, Allende A, Bennett RN, Ferreres F, Gil MI. 2006. Microbial, nutritional and sensory quality of rocket leaves as affected by different sanitizers. Postharvest Biol Tech 42: 86-97.

73. Mastebroek HD, Marvin HJP 2000. Breeding prospects of Lunaria annua L. Ind Crop Prod 11: 139-143.

74. Mewis I, Appel HM, Hom A, Raina R, Schultz JC. 2005. Major signaling pathways modulate Arabidopsis glucosilonate accumulation and response to both phloem-feeding and chewing insects. Plant Physiol 138: 1149-1162.

75. Miles PW. 1999. Aphid Saliva. Biol Rev 74: 41-85.

76. Mollers C, Nehlin L, Glimelius K, Iqbal MCM. 1999. Influence of in vitro culture conditions on glucosinolate composition of microsporederived embryos of Brassica napus. Physiol Plantarum 107: 441-446.

77. Monde K, Takasugi M, Shirata A. 1995. Three sulfur containing stress metabolites from Japanese radish. Phytochem 39: 581-2586.

78. Naznin HA, Kiyohara D, Kimura M, Miyazawa M, Shimizu M, and Hyakumachi M. 2014. Systemic Resistance Induced by Volatile Organic Compounds Emitted by Plant GrowthPromoting Fungi in Arabidopsis thaliana. PLoS ONE 9(1): e86882. doi:10.1371/journal. pone.0086882

79. Oerlemans K, Barrett DM., Suades CB, Verkerk R., Dekker M. 2006. Thermal degradation of glucosinolates in red cabbage. Food Chem 95: 19-29.

80. Oku, H, Shiraishi T. 1995. Phytoalexins and host specificity in plant disease. En: Handbook of phytoalexins metabolism and actions. Daniel, M, Purkayastha RP. Editorial Marcel Dekker Inc. USA.

81. Ortuño A, Báidez A, Gómez P, Arcas MC, Porras I, García-Lidón A, Del Río JA. 2006. Citrus paradisi and Citrus sinensis flavonoids: their 
influence in the defense mechanism against Penicillium digitatum. Food Chem 98: 351-358.

82. Pedras MSC, Smith KC. 1997. Sinalexin, a phytoalexin from white mustard elicited by destruxin B and Alternaria brassicae. Phytochem 46(5): 833-837.

83. Pedras, MSC, Sorensen JL, Okanga Fl, Zaharia IL. 1999. Wasalexins $A$ and $B$, new phytoalexins from wasabi: isolation, synthesis and antifungical activity. Bioorg Med Chem Lett 9: 3015-3020.

84. Pedras, MSC, Jha M, Ahiahonu PWK. 2003a. The synthesis and biosynthesis of phytoalexins produced by cruciferous plants. Curr Org Chem 7: 1635-1647.

85. Pedras MSC, Chumala PB, Suchy S. 2003b. Phytoalexins from Thlaspi arvense, a wild crucifer resistant to virulent Leptosphaeria maculans: structures, syntheses, and antifungal activity. Phytochem 64: 949-956.

86. Pedras MSC, Montaut S, Zaharia IL, Gai Y, Ward DE. 2003c. Transformation of the host-selective toxin destruxin B by wild crucifers: probing a detoxification pathway. Phytochem 64: 957-963.

87. Pedras MSC, Ahiahonu PWK. 2004. Phytotoxin production and phytoalexin elicitation by the phytopathogenic fungus Sclerotinia sclerotiorum. J Chem Ecol 30 (11): 2163-2179.

88. Pedras MSC, Montaut S, Suchy M. 2004. Phytoalexins from the crucifer rutabaga: structures, syntheses, byosyntheses, and antifungal activity. J Org Chem 69: 4471-4476.

89. Pedras MSC, Ahiahonu PWK. 2005. Metabolism and detoxification of phytoalexins and analogs by phytopathogenic fungi. Phytochemistry 66: 391-411.

90. Pedras MSC, Sarwar MG, Suchy M, Adio AM. 2006. The phytoalexins from cauliflower, caulilexins A, B and C: Isolation, structure determination, syntheses and antifungal activity. Phytochem 67: 1503-1509.
91. Pedras MSC, Gadagi RS, Jha M, Sarma-MamiIlapalle VK. 2007. Detoxification of the phytoalexin brassinin by isolates of Leptosphaeria maculans pathogenic on brown mustard involves an inducible hydrolase. Phytochem 68: 1572-1578.

92. Pedras MSC, Zheng Q, Gadagi RS, Rimmer SR. 2008, Phytoalexins and polar metabolites from the oilseeds canola and rapeseed: Differential metabolic responses to the biotroph Alburgo candida and to abiotic stress. Phytochem 69: 894-910.

93. Pedras MSC, Hossain S, Snitynsky RB. 2011. Detoxification of cruciferous phytoalexins in Spontaneous dimerization of a camalexin metabolite. Phytochem 72: 199-206.

94. Pérez RM, Pérez R. 2004. Raphanus sativus (Radish): Their chemistry and biology. The Scientific World Journal 4: 811-837.

95. Plaza GA, Pedraza M. 2007. Reconocimiento y caracterización ecológica de la flora arvense asociada al cultivo de uchuva. Agron Colomb 25(2): 306-313.

96. Pereira FMV, Rosa E, Fahey JW, Stephenson K, Carvalho R, Aires A. 2002. Influence of temperature and ontogeny on the levels of glucosinolates in broccoli (Brassica oleracea var. italica) sprouts and their effect on the induction of mammalian phase 2 enzymes. J Agr Food Chem 50: 6239-6244.

97. Radovich TJK, Kleinhenz MD, Streeter JG. 2005. Irrigation timing relative to head development influences yield components, sugar levels, and glucosinolate concentrations in cabbage. J Am Soc Hortic Sci 130: 943-949.

98. Reifenrath K., Müller C. 2007. Species-specific and leaf-age dependent effects of ultraviolet radiation on two Brassicaceae. Phytochem 68: 875-885.

99. Robbins RJ, Keck AS, Banuelos G, Finley JW. 2005. Cultivation conditions and selenium fertilization alter the phenolic profile, 
glucosinolate, and sulforaphane content of broccoli. J Med Food 8 (2): 204-214.

100. Rodov V, Ben-Yehoshua S, Fang DQ, Kim JJ, Ashkenazi R. 1995. Preformed antifungal compounds of lemon fruit: citral and its relation to disease resistance. Food Chem 43: 1057-1061.

101. Rouleau M, Marsolais F, Richard M, Nicolle L, Voigt B, Adam G, Varin L. 1999. Inactivation of brassinosteroid biological activity by a salicylate-inducible steroid sulfotransferase from Brassica napus. J Biol Chem 274 (30): 20925-20930.

102. Sakihama Y, Cohen MF, Grace SC, Yamasaki H. 2002. Plant phenolic antioxidant and prooxidant activities: phenolics-induced oxidative damage mediated by metals in plants. Toxicology 177: 67-80.

103. Salywon AM, Dierig DA, Rebman JP, de Rodríguez DJ. 2005. Evaluation of new Lesquerella and Physaria (Brassicaceae) oilseed germplasm. Am J Bot 92 (1): 53-62.

104. Sang JP, Minchinton IR, Johnstone PK, Truscott RJW. 1984. Glucosinolate profiles in the seed, root and leaf tissue of cabbage, mustard, rapeseed, radish and swede. Can JPlantSci64:77-93.

105. Schonhof I, Kläring HP, Krumbein A, Clauben W, Schreiner M. 2007. Effect of temperature increase under low radiation conditions on phytochemicals and ascorbic acid in greenhouse-grown broccoli. Agr Ecosyst Environ 119: 103-111.

106. Siemens DH, Garner SH, Mitchell-Olds T, Callaway RM. 2002. Cost of defense in the context of plant competition: Brassica rapa may grow and defend. Ecology 83: 505-517.

107. Sikora E, Cieslik E, Leszczynka T, Filipiak-Florkiewicz A, Pisulewski PM. 2008. The antioxidant activity of selected cruciferous vegetables subjected to aquathermal processing. Food Chem 107: 55-59.
108. Smith CJ. 1996. Accumulation of phytoalexins: defence mechanism and stimulus response system. New Phytol 132: 1-45.

109. Smolinska U, Morra MJ, Knudsen GR, James RL. 2003. Isothiocyanates produced by Brassicaceae species as inhibitors of Fusarium oxysporum. Plant Dis 87: 407-412.

110. Sønderby IE, Geu-Flores F, Halkier BA. 2010. Biosynthesis of glucosinolates - gene discovery and beyond. Trends Plant Sci 15: 283-290.

111. Song L, Thornaley PJ. 2007. Effect of storage, processing and cooking on glucosinolates content of Brassica vegetables. Food Chem Toxicol 45: 216-224.

112. Sousa C, Pereira DM, Pereira JA, Bento $A$ Rodrígues MA, Dopico-García S, Valentao P, Lopes G, Ferreres F, Seabra RM, Andrade PB. 2008. Multivariate analysis of Trochuda cabbage (Brassica oleracea L. var. costata DC) phenolics: influence of fertilizers. J Agr Food Chem 56 (6): 2231-2239.

113. Soylu S. 2006. Accumulation of cell wall bound phenolic compounds and phytoalexin in Arabidopsis thaliana leaves following inoculation with pathovars of Pseudomonas syringae. Plant Sci 170: 942-952.

114. Taiz L, Zeiger E. 2010. Plant Physiology. $5^{\text {Th }}$ edition. The Benjamin/Cummings. Redwood City, California. USA.

115. Takasugi M, Katsui N, Shirata A. 1986. Isolation of three novel sulfur-containing phytoalexins from the Chinese cabbage Brassica campestris L. ssp. pekinensis (Cruciferae). J Chem Soc 1077-1078.

116. Takasugi M, Monde K, Katsui N, Shirata A. 1987. Spirobrassinin, a novel sulfur-containing phytoalexin from the daikon Rhaphanus sativus L. var. hortensis (Cruciferae). Chem Lett 1631-1632.

117. Thakur M, Sohal B.S. 2013. Role of elicitors in inducing resistance in plants against pathogen infection: A review. ISRN Biochem 2013:1-10 
118- The Plant List, 2013. Version1.1.http://www.theplantlist.org/. Accedida el 18 de abril de 2013.

119. Troncoso R, Espinosa C, Sánchez-Estrada A, Tiznado ME, García HS. 2005. Analysis of the isothiocyanates present in cabbage leaves extract and their potential application to control Alternaria rot in bell peppers. Food Res Int 38: 701-708.

120. Vallejo F, Tomás-Barbéran FA, García-Viguera C. 2003. Healt-promoting compounds in broccoli as influenced by refrigerated transport and retail sale period. J Agr Food Chem 51: 3029-3034.

121. Vallejo F, García-Viguera C, Tomás-Barberán FA. 2003. Changes in broccoli (Brassica oleracea $\mathrm{L}$. var. italica) health-promoting compounds with inflorescence development. J Agr Food Chem 51 (13): 3776-3782.

122. Van-Dam NM, Raaijmakers CE. 2006. Local and systemic induced responses to cabbage root fly larvae (Delia radicum) in Brassica nigra and B. oleracea. Chemoecol 16: 17-24.

123. Van-Etten HD, Sandrock RW, Wasmann CC, Soby SD, McCluskey K, Wang P. 1995. Detoxification of phytoanticipins and phytoalexins by phytopathogeni fungi. Can J Bot 73 (1): 5518-5525.

124. Vereecke D, Messens E, Klarskov K, De-Bruyn A, Montagu MV, Goethals K. 1997. Patterns of phenolic compounds in leafy galls of tobacco. Planta Sci 201: 342-348.

125. Vig AP, Rampal G, Thind TS, Arora S. 2009. Bioprotective effects of glucosinolates $-A$ review. Food Sci Technol Int 42 (10): 1561-1572.

126. Volden J, Borge GIA, Bengtsson GB, Hansen $M$, Thygesen IE, Wicklund T. 2008. Effect of thermal treatment on glucosinolates and antioxidant-related parameters in red cabbage (Brassica oleracea L. ssp capitata f. rubra). Food Chem 109: 595-605.
127. Yaniv Z, Schafferman D, Zur M, Shamir I. 1997. Evaluation of Matthiola incana as a source of omega-3-linolenic acid. Ind Crop Prod 6: 285-289.

128. Walters D. 2010. What defenses do plants use? p 15- 75. En: Walters D. (Ed.). Plant defense: Warding off attack by pathogens, pests and vertebrate hervibores, Wiley-Blackwell, USA.

129. Warwick SI, Francis A, Al-Shehbaz IA. 2006. Brassicaceae: Specis checklist and database on CD-Rom. Plant Syst Evol 259: 249-258.

130. Warwick SI. 2011. Brassicaceae in Agriculture. p 33-66. En: Schmidt R, Bancroft I (Eds). Genetics and Genomics of the Brassicaceae. Springer, New York.

131. Wei K, Zhang F, Zhang Z. 2002. Behavior-modulating plant volatile Chemical for aphids. Chinese Sci Bull 47: 115-117.

132. Wilson KE, Thompson JE, Huner NPA, Greenberg BM. 2001. Effects of ultraviolet-A exposure on ultraviolet-B-induced accumulation of specific flavonoids in Brassica napus. Photochem Photobiol Sci 73 (6): 678-684.

133. Winkler S, Farangher J, Franz P, Imsic M, Jones R. 2007. Glucoraphanin and flavonoid levels remain stable during simulated transport and marketing of broccoli (Brassica oleracea var. italica) heads. Postharvest Biol Tec 43: 89-94.

134. Zhang H, Schonhof I, Krumbein A, Gutezeit B, Li L, Stuzel H, Schreiner M. 2008. Water supply and growing season influence glucosinolate concentration and composition in turnip root (Brassica rapa ssp rapifera L.). J Plant Nutr 171: 255-265. 